\title{
Growth, morphology, and biomass allocation of recently planted seedlings of seven European tree species along a light gradient
}

\author{
leva Bebre ${ }^{(1)}$, \\ Peter Annighöfer ${ }^{(2)}$, \\ Christian Ammer (1), \\ Dominik Seidel ${ }^{(1)}$
}

\begin{abstract}
Light is one of the most critical factors controlling tree survival and growth. Limited light availability induces phenotypic plasticity, thus enabling plants to adapt to suboptimal conditions. The plastic responses are species-specific and are thought to largely depend on species' shade tolerance. This study aims to add to existing research by trying to disentangle the effects of light, species identity, and shade tolerance on growth, biomass partitioning, and morphology of seedlings of seven common European tree species. For that purpose, we set up a shading experiment where seedlings were grown under three levels of light availability (15\%, 35\%, and $100 \%)$. A destructive harvest was carried out for the assessment of biomass allocation and structural complexity of plant architecture after a year of exposure to limited light. The specific leaf area increased with decreasing light availability for all species. However, we found little to no changes in relative height and diameter growth, biomass allocation to aboveground tree compartments, and structural complexity along the light gradient. We argue that because trees were grown under open field conditions, both in the nursery and for the first year of the experiment, it might have resulted in a delayed response to limited light availability. Assuming the delayed reaction of less plastic plant organs, we expect that the morphological adaptations of the tree species and intra- and interspecific differences will become more pronounced, as the trees grow older.
\end{abstract}

Keywords: Shade Tolerance, Plant Morphology, Fractal Analysis, Biomass Allocation, Specific Leaf Area, Light

\begin{abstract}
Introduction
Plant phenotypic plasticity is the natural consequence of their immobility (Borges 2008). Different biotic (e.g., competition, herbivory) and abiotic (e.g., light, temperature, soil conditions, water availability) environmental factors affect plant growth and induce phenotypic plasticity. The latter
\end{abstract}

(1) Department of Silviculture and Forest Ecology of the Temperate Zones, Faculty of Forest Sciences and Forest Ecology, GeorgAugust-University of Göttingen, Büsgenweg 1 , 37077 Göttingen (Germany); (2) Forest and Agroforest Systems, Technical University of Munich (TUM), Hans-Carl-von-Carlowitz-Platz 2, 85354 Freising (Germany)

\section{@ leva Bebre}

(ieva.bebre@uni-goettingen.de)

Received: Feb 07, 2020 - Accepted: May 05, 2020

Citation: Bebre I, Annighöfer P, Ammer C, Seidel D (2020). Growth, morphology, and biomass allocation of recently planted seedlings of seven European tree species along a light gradient. iForest 13: 261-269. doi: 10.3832/ifor3370-013 [online 2020-0703]

Communicated by: Claudia Cocozza reveals itself in the form of changes in plant morphology, biomass allocation patterns, or differences in the structural complexity of plant architecture (Pham \& McConnaughay 2013). Generally speaking, the plasticity of physiological or morphological traits is a beneficial characteristic as it enables a plant to adapt to suboptimal environmental conditions (Bradshaw 1965). Understanding the rates and expressions of the plasticity of various species and their relation to shade tolerance can help to improve the management of mixed forests, including continuous cover forestry.

Among the influential factors for phenotypic plasticity, light availability is recognized as one of the most important drivers, strongly controlling tree survival and growth (Pacala et al. 1994, Minotta \& Pinzauti 1996, Claveau et al. 2002). Additionally, the net competitive ability (i.e., strategical growth response as a result of resource limitation) is found to be different between species (Lambers et al. 2008). One of the most important determinants of these differences is species' shade tolerance. Shade tolerance is, to a large extent, dependent on the plasticity of light-harvesting organs (Valladares et al. 2007), and is often quantified either as the ability to survive or as the rate of growth when a given resource is extremely limited (Walters \& Reich 1996). However, shade tolerance is a complex and specific adaptation
(Gommers et al. 2013). Some authors even argue that it should not be perceived as an absolute value, but rather a relative concept that depends on specific ecological context (e.g., a co-existence of multiple biotic and abiotic stressors) and ontogenic stage (Valladares \& Niinemets 2008). Although species shade tolerance has been widely investigated, there still appears to be a lack of consensus regarding the relevant traits through which species adapt to low-light environments (Valladares \& Niinemets 2008).

Delagrange et al. (2004) studied the physiological, morphological, and allocational plasticity of trees under different light levels. They concluded that single traits such as leaf area ratio, maximal stomatal conductance, crown height to crown diameter ratio, or leaf nitrogen concentration cannot explain the interspecific differences in shade tolerance. Hence, the concept of shade tolerance remains a rather qualitative one, and the question of what shade tolerance specifically is still prevails. Is it only related to species' ability to survive in low-light environments, or does the concept encompass interactions between fluctuations in environmental conditions and a plant's phenotypic plasticity? Understanding the light requirements of different species allows creating favorable conditions for desired mixtures and ensuring more successful regeneration practices 
(Petritan et al. 2009). Therefore, further indepth studies are required to test the regulatory mechanisms on multiple levels, i.e., morphological, anatomical, physiological, and molecular.

Resource availability affects growth (Endara \& Coley 2011), biomass allocation (Canham et al. 1996), and the structural complexity of plants (Archibald \& Bond 2003). For most species, height growth, diameter growth, and overall biomass production are positively related to increased light availability (Minotta \& Pinzauti 1996, Messier \& Nikinmaa 2000, Sevillano et al. 2016). However, the growth strategies of plants differ and are dependent on species identity (Annighöfer et al. 2017). Shade-tolerant species are expected to grow slower and use the available resources more conservatively, whereas light-demanding species are expected to exhibit higher growth rates and avoid shade when the light availability is limited (Prasad 1997). These differences persist both in low- and high-light en vironments because of the higher photosynthetic plasticity of light-demanding species (Pothier \& Prévost 2002). Higher photosynthetic plasticity allows plants to use light more efficiently, even if the light availability is limited (Valladares et al. 2007).

Resource availability also affects the allocational plasticity of plants. Biomass allocation varies between species, environments, and over time (Poorter et al. 2012). More over, according to the balanced growth hypothesis (Shipley \& Meziane 2002), plants are expected to allocate more biomass to wards the organ that is responsible for ac quiring the limited resource. For example, in case of limited light availability, plants will allocate more biomass towards the aboveground (Kozlowski \& Pallardy 1997), preferably to leaves or needles (Poorter 1999).

Leaves and needles are considered the most plastic organs, and in low-light conditions, trees firstly tend to adapt by changing their leaf morphology (Poorter et al. 2012). Against this background, specific leaf area (SLA) is typically found to increase with decreasing light availability (Minotta \& Pinzauti 1996, Reich et al. 1998, Janse-Ten Klooster et al. 2007). Moreover, SLA of shade-tolerant species is usually higher than of light-demanding ones (Delucia et al. 1998, Petritan et al. 2009, Sevillano et al. 2016).

Changes in allocation patterns also translate into changed structural complexity, e.g., light-demanding species tend to invest more in leaf area and stem elongation (Zhang et al. 2016), thus directly influencing the structural complexity of the plant architecture. The structural complexity of a plant directly relates to how the plant occupies space and intercepts light (Reffye et al. 1995). Accordingly, plants are expected to form structurally more complex branching patterns when the light availability is not limited (Archibald \& Bond 2003, Seidel et al. 2019a). The box-dimension values de- rived from fractal analysis can be used to assess structural complexity of plant architecture (Mandelbrot 1982, Seidel 2018). Increased structural complexity translates into higher box-dimension values that are derived from the number of different-sized voxels fit to a 3D tree model (Seidel 2018).

A plethora of studies has analyzed the influence of light availability on tree growth and biomass allocation, but the findings are still divergent. Species' shade tolerance rankings, in terms of growth and biomass allocation, are mostly consistent (JanseTen Klooster et al. 2007, Van Couwenberghe et al. 2013). However, numerous studies found responses to light in the expression of one or more traits that did not follow traditional shade tolerance rankings (Chen 1997, Delagrange et al. 2006).

This paper presents the results from the first two years of a long-term experiment studying seedlings of seven common European tree species growing along a light gradient. The study seeks to add to the existing research by trying to disentangle the effects of light, species identity, and shade tolerance on growth, biomass partitioning, and structural complexity of common hornbeam (Carpinus betulus L.), European beech (Fagus sylvatica L.), Norway spruce (Picea abies [L.] H. Karst.), Scots pine (Pinus sylvestris L.), sessile oak (Quercus petraea [Matt.] Liebl.), silver fir (Abies alba Mill.), and sycamore maple (Acer pseudoplatanus L.). Additionally, it attempts to test the shade tolerance rankings introduced by Ellenberg \& Leuschner (2010), according to which the studied species can be arranged in the following order of decreasing shade tolerance: $F$. sylvatica $(3)=$ A. alba (3) $>$ C. betulus (4) = A. pseudoplatanus (4) $>$ P. abies (5) $>$ Q. petrea (6) $>$ P. sylvestris (7).

The following hypotheses were tested:

1. Height and diameter growth: (1.1) relative height and diameter growth differ between species; (1.2) relative height and diameter growth increase with increasing light availability; (1.3) relative height and diameter growth increase more strongly for light-demanding species.

2. Biomass production and allocation: (2.1) total biomass increases with increasing light availability and the increase is stronger for light-demanding species; (2.2) root mass fraction (RMF) increases and leaf mass fraction (LMF) decreases with increasing light availability; (2.3) branch mass fraction (BMF) increases with increasing light availability for lightdemanding species but remains constant for shade-tolerant species.

3. Leaf and plant morphology: (3.1) SLA increases with decreasing light availability; (3.2) shade-tolerant species have higher SLA; (3.3) structural complexity increases with increasing light availability; (3.4) the structural complexity of light-demanding species increases more with increasing light availability.

\section{Materials and methods}

\section{Study site and experimental setup}

This study was conducted in a controlled shading experiment located at the North Campus of the University of Göttingen, Germany ( $51^{\circ} 33^{\prime} 34.5^{\prime \prime} \mathrm{N}, 09^{\circ} 57^{\prime} 34.8^{\prime \prime} \mathrm{E}$ ). The study site is located $234 \mathrm{~m}$ above sea level. According to Köppen-Geiger climate classification, the climate is temperate and oceanic. The average annual temperature is $9.2{ }^{\circ} \mathrm{C}$, and the annual average precipitation reaches $650 \mathrm{~mm}$, of which $310 \mathrm{~mm}$ falls between May to September (http:// www.dwd.de).

Eighty centimeters $(80 \mathrm{~cm})$ of topsoil were dug out, mixed with homogeneous sand (2:1), and filled back in up to the ground level to create homogeneous growth conditions. The soil was covered with a fabric sheet of woven weed control membrane to avoid the emergence of competing vegetation. An automatic dripping irrigation system was installed, and all seedlings received the same water treatment. The soil was kept moist so that light was the only limited resource. Precipitation was able to reach the seedlings, thus providing additional water.

The shading experiment was established for seven common European tree species, i.e., F. sylvatica, A. alba, A. pseudoplatanus, C. betulus, P. abies, Q. petrea, and P. sylvestris.

The planting material was obtained from August Lüdemann Forst und Landschaftservice $\mathrm{GmbH}$ (Frankfurt, Germany). P. sylvestris seedlings were one year old and the seedlings of all the other species - twoyear-old. The seedlings were not transplanted or undercut. All seedlings were bareroot and their initial size ranged from $30-50 \mathrm{~cm}$, on average.

The seedlings were planted in November 2016. During the first year, plants grew under open field conditions to avoid high initial mortality of the light-demanding species. In the second year, shading nets of different light permeability were installed on metal frames (height: $8 \mathrm{~m}$ ) to create two additional light availability levels of $35 \%$ and $15 \%$ of the ambient light. The light levels were chosen based on the findings in literature (Walters \& Reich 1996, Delagrange et al. 2006). It was aimed to expose seedlings to low enough light availability (15\%) to study shifts in biomass allocation patterns, while avoiding high mortality of light-demanding species in long-term. The intermediate light level (35\%) was chosen to represent good growth conditions for shade-tolerant species, some of which already saturate in growth above the given level (e.g., beech - Collet \& Chenost 2006). Ambient light $(100 \%)$ conditions we provided as the other extreme of unlimited light availability.

Irradiance was measured in every compartment both in an open field (control) and under the shading nets using the LICOR QUANTUM ${ }^{\circledast}$ sensor (LI-COR Biosci- 
ences, Nebraska, USA) to control for the specified shading effect of the nets. Light availability was expressed as the percentage of irradiance passing through the shading nets in comparison to open field conditions.

The experiment was arranged in two levels - by light availability and by subplot (Fig. 1). Each of the three light availability levels (15\%, 35\%, and $100 \%$ ) was assigned randomly to different shading halls. Subplots (Subplot 1 - Subplot 5) were used to categorize the experimental units by the time of the planned biannual seedling harvests, ranging from 2-10 years after planting. Seedlings were provided with enough growing space to insure that even after 10 years the competition would be excluded. Thus, seedlings in Subplot 1 (harvested for this study) each occupied $0.36 \mathrm{~m}^{2}$. The growing space for seedlings that will be harvested after $4,6,8$, and 10 years was $0.71 \mathrm{~m}^{2}, 1.43 \mathrm{~m}^{2}, 3.21 \mathrm{~m}^{2}$, and $5.71 \mathrm{~m}^{2}$ per seedling, respectively. Against that background, the planting distances and the number of rows also varied by the subplot, (Subplot 1 and 2: 1 row, 0.7 m; Subplot 3: 2 rows, $1.0 \times 1.4 \mathrm{~m}$; Subplot 4: 3 rows, $1.2 \times 2.2$ m; Subplot 5: 4 rows, $1.6 \times 2.5 \mathrm{~m}-$ Fig. 1 ). Each experimental unit (" $\mathrm{n} \%$ light" $\times$ "Subplot n", n=60) was comprised of 14 seedlings - two of each of the seven species and replicated four times. The seedlings were planted in a random order within each experimental unit. In total, 120 seedlings per species were planted, i.e., 40 seedlings per light availability level.

\section{Sampling procedure}

The height and diameter of each seedling were measured for two years at the end of the vegetation period. Height was measured using a folding ruler (Accuracy Class III). Diameter was measured as root collar diameter $5 \mathrm{~cm}$ above ground using a digital caliper (RS PRO 150mm Digital Caliper, accuracy $\pm 0.03 \mathrm{~mm}$ ). Height and diameter measurement data from all seedlings were included in the data analysis ( 5 subplots $\times 3$ light levels $\times 7$ species $\times 8$ seedlings $=840$ ).

Destructive harvest was carried out for a subset (Subplot 1 - see Fig. 1) of 168 seedlings ( 3 light levels $\times 7$ species $\times 8$ seedlings $=168$ ) at the end of the second vegetation period after planting, in November 2018. Leaves of the deciduous seedlings were harvested before the seedling harvest. Whereas for coniferous seedlings, the removal of needles took place in the lab after the whole-seedling harvest. A representative sample of 20 leaves or needles was collected and scanned for the leaf area estimates with an office-type scanner Medion MD $90093^{\circledast}$ (MEDION, Essen, Germany). The remaining leaves and needles were also removed, dried to constant weight, and weighted.

After the harvest and leaf or needle removal, all seedlings were scanned in the laboratory using a Faro Focus ${ }^{\circledR}$ 3D 120 (Faro Technologies, Lake Mary, FL, USA) terrestrial laser scanner. The seedlings were prepared for laser scanning by washing and consecutively air-drying for a short period, to avoid increased laser beam reflection when beams hit drops of water. Seedlings were mounted on a support stand with a two-prong clamp. Seedlings were adjusted so that the roots were hanging in the air and did not touch any objects. The root collar was in the middle of the prongs to provide a clear marker in the scan data. All seedlings were scanned using a multi-scan approach at four fixed scanning points at equal distance from the seedling according to the corners setup introduced in Van Der Zande et al. (2008) but without the center scan.

After scanning, seedlings were partitioned into roots, stems, and branches and dried at $70{ }^{\circ} \mathrm{C}$ for at least 48 hours until a constant weight was reached. After drying, all the compartments were weighed. Leaf/needle, branch, stem, and root dry mass were determined to the milligram using a standard laboratory scale Sartorius MC1 LC1200S ${ }^{\circledast}$, accuracy \pm 0.003 g (Sartorius AG, Göttingen, Germany).

\section{Data processing}

Leaf and needle area were determined by processing the scanned images with the software WinFolia 2004a (Régent Instruments Inc., Quebec, Canada). SLA ( $\left.\mathrm{cm}^{2} \mathrm{~g}^{-1}\right)$ was calculated as the leaf area divided by the oven-dry leaf mass.

Relative height $\left(\mathrm{cm} \mathrm{cm}^{-1}\right)$ and diameter $\left(\mathrm{mm} \mathrm{mm}^{-1}\right)$ growth between years 2018 and 2017 and biomass fractions ( $\mathrm{g} \mathrm{g}^{-1}$ ) were calculated for a more detailed analysis of interspecific differences in growth and biomass allocation along the light gradient. Following formulas were used to calculate the specific leaf area (SLA, $\mathrm{cm}^{2} \mathrm{~g}^{-1}$ - eqn. 1), relative growth (Rel_hinc: relative height increment, $\mathrm{cm} \mathrm{cm}^{-1}$ - eqn. 2; and Rel_dinc: relative diameter increment, $\mathrm{mm} \mathrm{mm}^{-1}$ eqn. 3), and biomass allocation (tCMF: tree compartment mass fraction, $\mathrm{g} \mathrm{g}^{-1}-$ eqn. 4 ):

$$
\begin{aligned}
& S L A=\frac{L A}{L M_{d}} \\
& R e l_{-} h i n c=\frac{\left(h_{18}-h_{17}\right)}{h_{17}} \\
& R e l_{-} \text {dinc }=\frac{\left(d_{18}-d_{17}\right)}{d_{17}} \\
& t C M F=\frac{B M \_t C}{B M_{-} t o t}
\end{aligned}
$$

where LA is the leaf area $\left(\mathrm{cm}^{2}\right), \mathrm{LM}_{d}$ is the oven-dry leaf mass $(\mathrm{g}), \mathrm{h}_{18}$ is the height in November $2018(\mathrm{~cm}), h_{17}$ is the height in

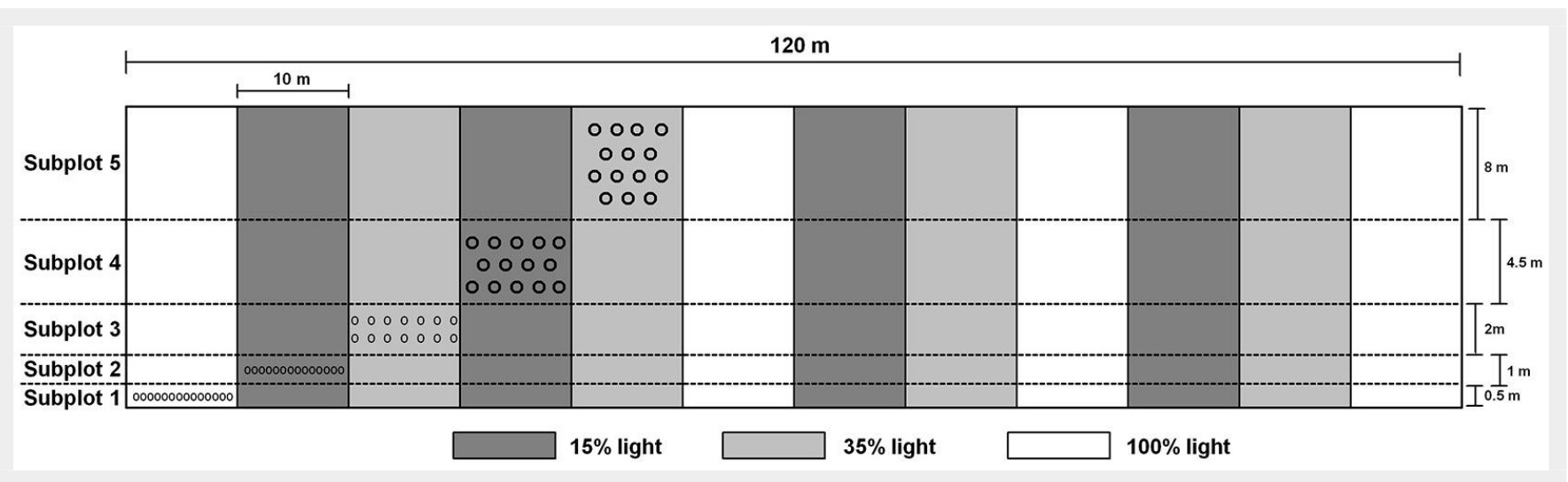

Fig. 1 - The layout of the shading experiment. The experiment is arranged in two levels - by light availability and by subplot. There are three light availability levels (15\%, 35\%, and 100\%), each replicated four times and assigned randomly to different shading halls. Additionally, the Subplot 1 - Subplot 5 are used to categorize the experimental units by the time of the planned biannual seedling harvests, ranging from 2-10 years after planting. Each experimental unit ("n\% light" × "Subplot n", n=60) is comprised of 14 seedlings - two of each of the seven tree species - and replicated four times. Planting distances and the number of rows vary by the subplot to provide enough space for seedlings that will have to grow for a longer period (Subplot 1 and $2: 1 \mathrm{row}, 0.7 \times 0.7 \mathrm{~m}$; Subplot 3: 2 rows, $1.0 \times 1.4 \mathrm{~m}$; Subplot 4: 3 rows, $1.2 \times 2.2 \mathrm{~m}$; Subplot 5: 4 rows, $1.6 \times 2.5 \mathrm{~m}$ ). The seedlings of different species are planted in a random order within each experimental unit. In total, 120 seedlings per species were planted, i.e., 40 seedlings per light availability level. 
November $2017(\mathrm{~cm}), \mathrm{d}_{18}$ is the diameter in November $2018(\mathrm{~mm}), d_{17}$ is the diameter in November 2017 (mm), BM tC is the ovendry biomass of a tree compartment, i.e., leaves/needles, branches, stems or roots (g), BM_tot is the oven-dry total plant biomass (g).

The spatial registration of the scans was based on four chessboard-style targets (Seidel et al. 2011) and was done automatically using the software Faro Scene ${ }^{\circledR} 7$ (Faro Technologies, Lake Mary, Florida, USA). For easier handling of the scans, the resolution was reduced to $1 / 16$ of the original resolution, thus keeping it high enough to carry out analysis but allowing easier and faster processing. All scans were filtered using the standard filter settings of Faro Scene and exported as xyz-files.

Open source 3D point cloud processing software Cloud Compare v. 2.10.1 (http:// www.cloudcompare.org) was used to further process the xyz-files. The seedlings were virtually cut out from the point cloud. They were divided in above and below

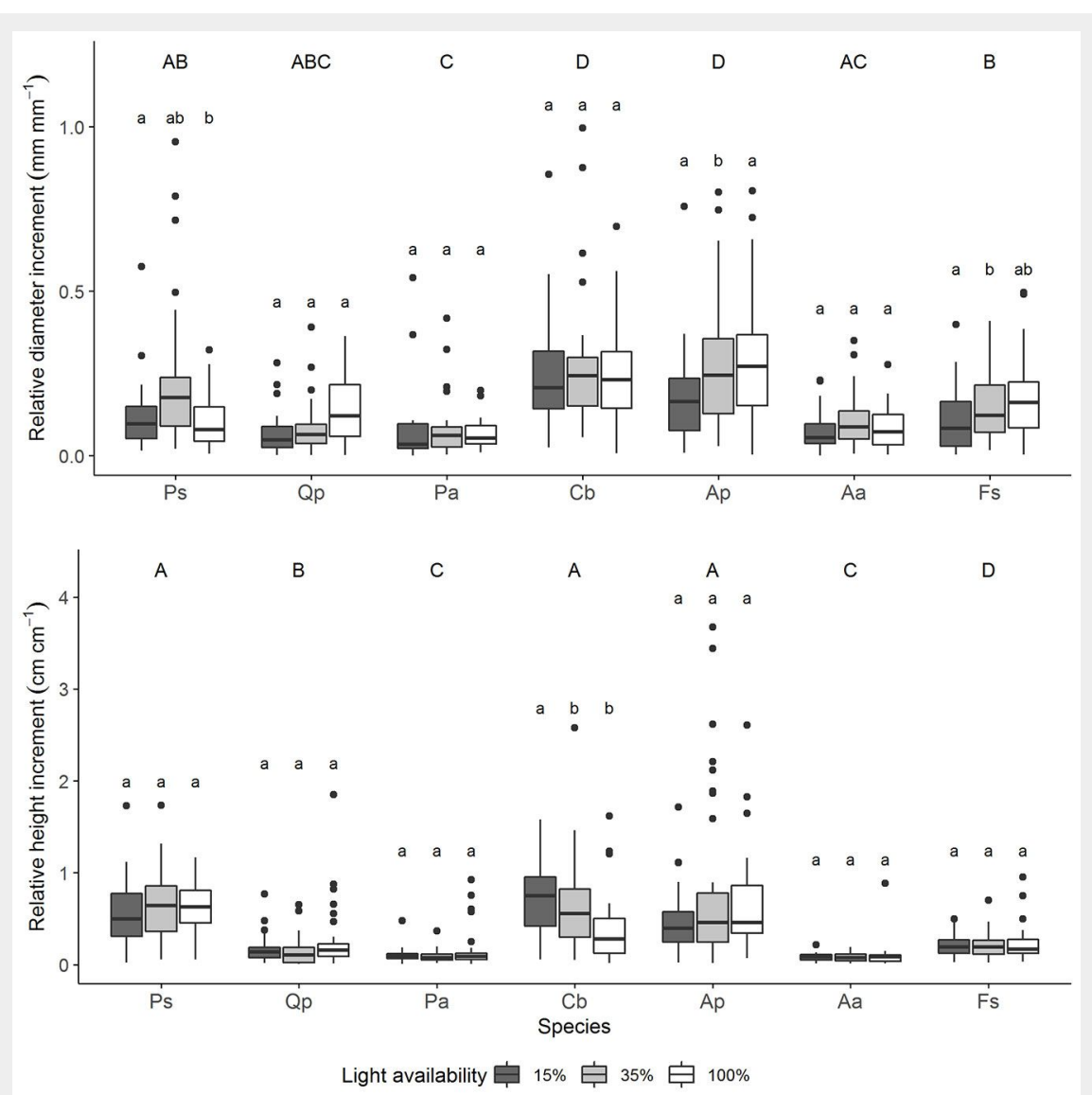

Fig. 2 - Intra- and interspecific differences in relative height $\left(\mathrm{cm} \mathrm{cm}^{-1}\right)$ and diameter $(\mathrm{mm} \mathrm{mm})$ growth. Uppercase letters indicate significant interspecific differences between relative height and diameter growth, irrespective of light availability $(n=120)$. Lowercase letters indicate significant intraspecific differences between relative height and diameter growth along the light gradient $(n=40)$. Relative diameter or height growths with the same letter are not significantly different between the species or within species between different light levels. Light availability ranges from $15 \%-100 \%$. Species are arranged from the least to the most shade-tolerant, according to Ellenberg \& Leuschner (2010). Species: Ps - P. sylvestris < Qp - Q. petrea $<P a-P$. abies $<C b-C$. betulus $=A p-A$. pseudoplatanus $<A a-A$. alba $=F s-F$. sylvatica. The $y$-axis scale of the two graphs is different. against inverse values of box sizes used to cover the whole plant. All the values are logarithmically transformed, and the slope of the fitted straight line corresponds to the box-dimension value of an object. For details, consult Seidel (2018).

\section{Statistical analysis}

Shapiro-Wilk test and visual assessment (histograms) were used to check for normal distribution of the data. Levene's test was applied to assess the assumption of variance homogeneity. Significant differences in growth responses, biomass allocation patterns, and structural complexity were tested with Kruskal-Wallis non-parametric test, as the data was not normally distributed, and the variance homogeneity could not be assumed. The differences were tested both between species and across different light levels as well as within species between different light levels and between species across different light levels. Whenever differences were significant, a pairwise Wilcoxon rank-sum test with Bonferroni adjustment was used as a post-hoc test to calculate comparisons between the groups.

On two occasions, for the SLA of $P$. sylvestris and interspecific comparison of belowground box-dimensions at 100\% light availability, the p-values from Kruskal-Wallis test showed significant differences. In contrast, the post-hoc test did not reveal which groups are different from one another. This outcome is most likely due to Bonferroni adjustment since it is known to be one of the most conservative adjustments for family-wise error.

The significance level for all tests was $p \leq$ 0.05 . All statistical analyses and tests were performed in the free software environment $R$ version 3.5.2 ( $R$ Development Core Team).

\section{Results}

\section{Growth}

Relative height and diameter growth were significantly different between species, irrespective of light availability $(p<0.001$ - Fig. 2). Relative height growth ranged from $60 \%$ for $P$. sylvestris, C. betulus, and $A$. pseudoplatanus down to $10 \%$ for $P$. abies and $A$. alba, on average. The relative height increment of $P$. sylvestris was significantly higher than the relative height increment of the less shade-tolerant conifer species P. abies and A. alba ( $p<0.001$ - Fig. 2). A comparable relationship was not observed between deciduous species or when pooling all tree species.

C. betulus and $A$. pseudoplatanus had the highest relative diameter growth, whereas Q. petrea, P. abies, and A. alba had the lowest one, on average (Fig. 2). No relationship between species' shade tolerance and higher or lower relative diameter increment was observed.

Relative height growth did not increase with increasing light availability across spe- 
cies and was $35 \%$, on average (Fig. 2). Only for $C$. betulus, an increase in relative height growth along the light gradient could be detected $(p<0.001)$.

Light availability affected relative diameter growth of $F$. sylvatica, A. pseudoplatanus, and $P$. sylvestris seedlings $(p<0.05)$, but only the relative diameter growth of $P$. sylvestris increased along the light gradient (Fig. 2). In other cases, there were no significant differences between the relative diameter increment at $15 \%$ and $100 \%$ light availability.

Since there was no pronounced effect of light on the seedling growth, it was not possible to test if the relative height and diameter growth increases more strongly for the light-demanding species.

\section{Biomass production and allocation}

There were inter- and intra-specific differences between the total biomass and along the light gradient. An increase in total biomass with increasing light availability could be detected for F. sylvatica, $C$. betulus, P. abies, and P. sylvestris ( $\mathrm{p}<0.05-$ Fig. 3).

The total biomass of A. alba, A. pseudoplatanus, and $P$. abies was on average by 67 grams higher than the total biomass of the

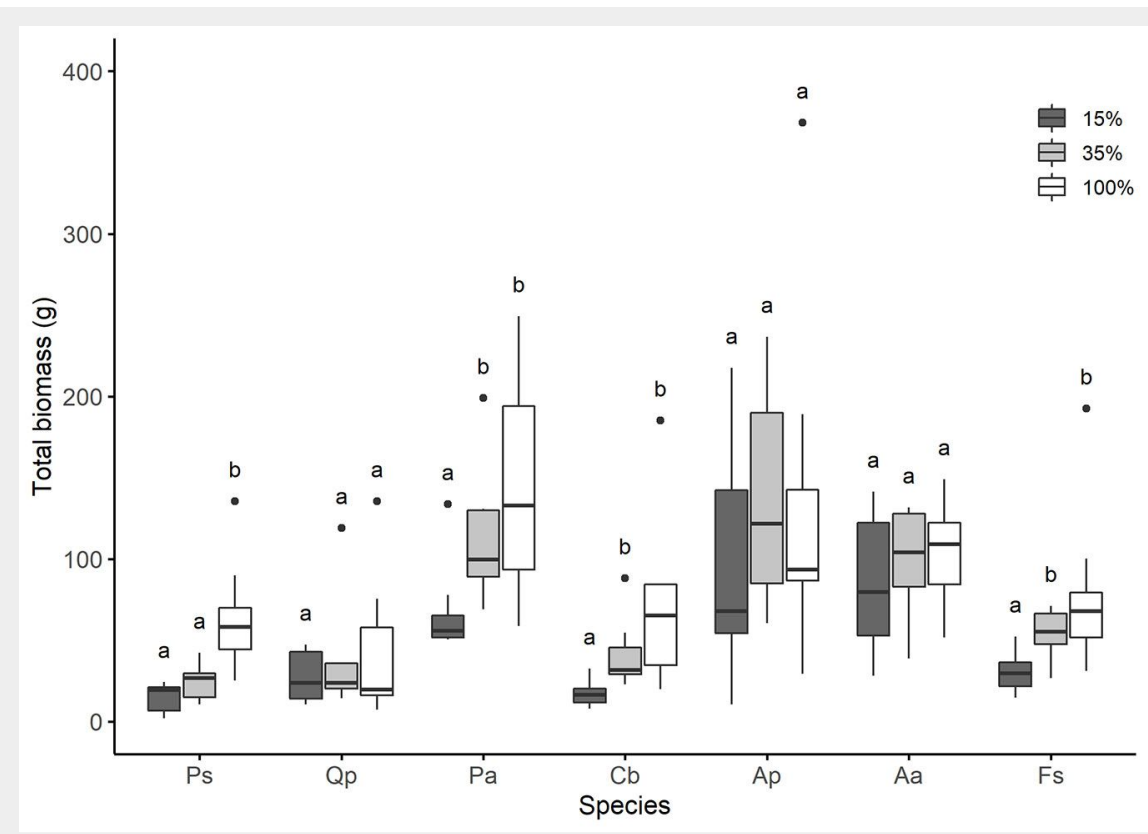

Fig. 3 - Total biomass (g) along the light gradient. Letters indicate significant differ ences of mean total biomass ( $g$ ) within species between different light levels $(n=8)$. Species are arranged from the least to the most shade-tolerant, according to Ellenberg \& Leuschner (2010). Species: Ps - P. sylvestris $<$ Qp - Q. petrea $<P a-P$. abies $<C b$ C. betulus = Ap - A. pseudoplatanus $<A a-A$. alba $=$ Fs - F. sylvatica.

Tab. 1 - Mean biomass fractions by species and light levels. Results are presented as mean values of respective plant mass fractions $\left(\mathrm{g} \mathrm{g}^{-1}\right) \pm$ standard deviation (SD). Letters indicate significant differences. Biomass fractions of species with the same letter are not significantly different. For intraspecific comparisons, no letters mean no intraspecific differences. Species are arranged from the least to the most shade-tolerant, according to Ellenberg \& Leuschner (2010). Species: Ps - P. sylvestris < Qp - Q. petrea < Pa - P. abies < $\mathrm{Cb}-$ C. betulus = Ap - A. pseudoplatanus < Aa - A. alba = Fs - F. sylvatica. (LMF): Needle/leaf mass fraction (g g-1) \pm SD; (BMF): branch mass fraction $\left(\mathrm{g} \mathrm{g}^{-1}\right) \pm \mathrm{SD}$; (SMF): stem mass fraction $\left(\mathrm{g} \mathrm{g}^{-1}\right) \pm \mathrm{SD}$; (RMF): root mass fraction $\left(\mathrm{g} \mathrm{g}^{-1}\right) \pm \mathrm{SD}$; (IntraS): intraspecific comparison within species and between light levels; (InterS): interspecific comparison between species and light levels.

\begin{tabular}{|c|c|c|c|c|c|c|c|c|c|c|c|c|c|}
\hline 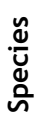 & $\begin{array}{l}\text { Light } \\
\text { (\%) }\end{array}$ & LMF & 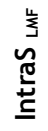 & 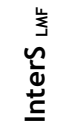 & BMF & 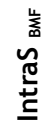 & 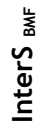 & SMF & 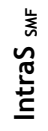 & 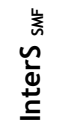 & RMF & 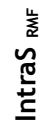 & 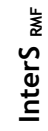 \\
\hline \multirow[t]{3}{*}{ Ps } & 15 & $0.36 \pm 0.18$ & - & $a b$ & $0.05 \pm 0.04$ & $a$ & $a b$ & $0.30 \pm 0.08$ & - & $a$ & $0.29 \pm 0.13$ & - & $a b$ \\
\hline & 35 & $0.41 \pm 0.06$ & - & $a$ & $0.06 \pm 0.02$ & $a$ & $a$ & $0.27 \pm 0.04$ & - & $\mathrm{a}$ & $0.26 \pm 0.05$ & - & a \\
\hline & 100 & $0.37 \pm 0.06$ & - & a & $0.10 \pm 0.02$ & $b$ & $a b$ & $0.26 \pm 0.06$ & - & $\mathrm{a}$ & $0.26 \pm 0.07$ & - & a \\
\hline \multirow[t]{3}{*}{$Q p$} & 15 & $0.11 \pm 0.05$ & - & a & $0.03 \pm 0.01$ & $\mathrm{a}$ & $\mathrm{a}$ & $0.29 \pm 0.08$ & $a$ & $\mathrm{a}$ & $0.57 \pm 0.07$ & - & c \\
\hline & 35 & $0.13 \pm 0.01$ & - & b & $0.02 \pm 0.01$ & $b$ & $\mathrm{~b}$ & $0.24 \pm 0.06$ & $a b$ & $a b c$ & $0.61 \pm 0.06$ & - & b \\
\hline & 100 & $0.13 \pm 0.04$ & - & bc & $0.03 \pm 0.03$ & $a b$ & $\mathrm{~cd}$ & $0.19 \pm 0.03$ & $\mathrm{~b}$ & $a b$ & $0.64 \pm 0.08$ & - & b \\
\hline \multirow[t]{3}{*}{$\mathrm{Pa}$} & 15 & $0.21 \pm 0.09$ & - & $a b$ & $0.16 \pm 0.03$ & - & c & $0.25 \pm 0.06$ & - & $\mathrm{a}$ & $0.37 \pm 0.06$ & - & $\mathrm{a}$ \\
\hline & 35 & $0.25 \pm 0.02$ & - & c & $0.14 \pm 0.02$ & - & c & $0.19 \pm 0.03$ & - & bd & $0.42 \pm 0.05$ & - & c \\
\hline & 100 & $0.23 \pm 0.05$ & - & d & $0.14 \pm 0.02$ & - & e & $0.19 \pm 0.04$ & - & $a b$ & $0.44 \pm 0.04$ & - & c \\
\hline \multirow[t]{3}{*}{$C b$} & 15 & $0.18 \pm 0.05$ & - & $a b$ & $0.09 \pm 0.03$ & - & $\mathrm{b}$ & $0.28 \pm 0.06$ & - & $d$ & $0.45 \pm 0.07$ & - & $a b c$ \\
\hline & 35 & $0.19 \pm 0.02$ & - & $d$ & $0.06 \pm 0.01$ & - & $a$ & $0.31 \pm 0.07$ & - & $\mathrm{ac}$ & $0.44 \pm 0.08$ & - & $\mathrm{cd}$ \\
\hline & 100 & $0.18 \pm 0.03$ & - & bd & $0.07 \pm 0.02$ & - & ac & $0.26 \pm 0.06$ & - & $\mathrm{a}$ & $0.48 \pm 0.08$ & - & c \\
\hline \multirow[t]{3}{*}{$A p$} & 15 & $0.18 \pm 0.06$ & - & $a b$ & $0.02 \pm 0.02$ & - & $\mathrm{a}$ & $0.35 \pm 0.09$ & $a$ & $\mathrm{a}$ & $0.46 \pm 0.14$ & $a b$ & $a b c$ \\
\hline & 35 & $0.21 \pm 0.04$ & - & $\mathrm{cd}$ & $0.01 \pm 0.01$ & - & $\mathrm{b}$ & $0.35 \pm 0.05$ & $\mathrm{a}$ & $c$ & $0.43 \pm 0.06$ & $a$ & $\mathrm{~cd}$ \\
\hline & 100 & $0.18 \pm 0.03$ & - & bd & $0.01 \pm 0.01$ & - & $\mathrm{a}$ & $0.22 \pm 0.09$ & $\mathrm{~b}$ & $a b$ & $0.58 \pm 0.09$ & $\mathrm{~b}$ & bc \\
\hline \multirow[t]{3}{*}{$A a$} & 15 & $0.23 \pm 0.02$ & - & b & $0.16 \pm 0.02$ & - & c & $0.15 \pm 0.02$ & - & $b$ & $0.46 \pm 0.03$ & - & bc \\
\hline & 35 & $0.24 \pm 0.02$ & - & c & $0.14 \pm 0.02$ & - & $c$ & $0.14 \pm 0.03$ & - & d & $0.48 \pm 0.04$ & - & $\mathrm{cd}$ \\
\hline & 100 & $0.23 \pm 0.13$ & - & abcd & $0.14 \pm 0.03$ & - & be & $0.13 \pm 0.04$ & - & $b$ & $0.50 \pm 0.10$ & - & bc \\
\hline \multirow[t]{3}{*}{ Fs } & 15 & $0.12 \pm 0.02$ & - & a & $0.10 \pm 0.02$ & - & $b$ & $0.27 \pm 0.03$ & - & $\mathrm{a}$ & $0.51 \pm 0.03$ & - & $b c$ \\
\hline & 35 & $0.14 \pm 0.02$ & - & b & $0.08 \pm 0.02$ & - & $\mathrm{a}$ & $0.25 \pm 0.04$ & - & $a b$ & $0.53 \pm 0.05$ & - & bd \\
\hline & 100 & $0.12 \pm 0.03$ & - & c & $0.09 \pm 0.02$ & - & $a b$ & $0.26 \pm 0.09$ & - & $\mathrm{a}$ & $0.53 \pm 0.11$ & - & $\mathrm{bc}$ \\
\hline
\end{tabular}



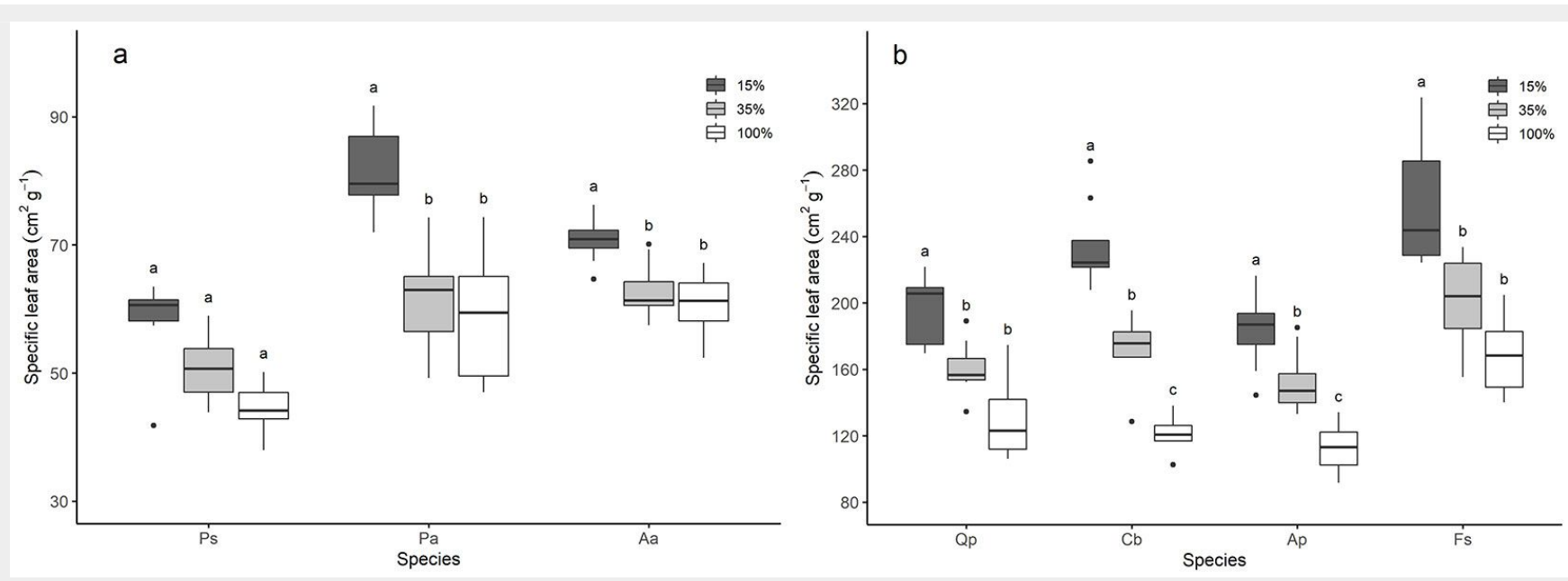

Fig. 4 - Specific leaf area (SLA, $\mathrm{cm}^{2} \mathrm{~g}^{-1}$ ) of the studied conifer (a) and deciduous (b) tree species. Letters indicate significant differences of SLA within species between different light levels $(n=8)$. SLA of species with the same letter is not significantly different between the light levels. Species are arranged from the least to the most shade-tolerant, according to Ellenberg \& Leuschner (2010). Species: Ps - P. sylvestris < Qp - Q. petrea $<P a-P$. abies $<C b-C$. betulus = Ap - A. pseudoplatanus $<A a-A$. alba $=F s-F$. sylvatica. The $y$-axis scale of the two graphs is different.

other species across all light levels. However, at $100 \%$ light availability, the interspecific differences in total biomass became less pronounced, compared to the lower light levels. Even though A. alba, A. pseudo-

platanus, and P. abies still had the highest total biomass, it was no longer significantly different from the other species (Fig. 3).

No relationship was detected between species' shade tolerance rankings and total

Tab. 2 - Above- and below-ground box-dimensions $\left(D_{b}\right)$ by species and light levels. Results are presented as the mean above and belowground box-dimension values \pm standard deviation (SD). Letters indicate significant differences. Box dimensions of species with the same letter are not significantly different. Species are arranged from the least to the most shade-tolerant, according to Ellenberg \& Leuschner (2010). Species: $P s$ - P. sylvestris $<Q p-Q$. petrea $<P a-P$. abies $<C b-C$. betulus $=A p-A$. pseudo platanus $<A a-A$. alba $=F s-F$. sylvatica. $\left(A G D_{b}\right)$ : aboveground box-dimension $\pm S D ;(B G$ $D_{b}$ ): aboveground box-dimension \pm SD; (IntraS): intraspecific comparison within species and between light levels - no letters at intraspecific comparisons mean that there were no significant differences; (InterS): interspecific comparison between species and light levels.

\begin{tabular}{|c|c|c|c|c|c|c|c|}
\hline Species & $\begin{array}{l}\text { Light } \\
\text { (\%) }\end{array}$ & $A G D_{b}$ & IntraS & InterS & $B G D_{b}$ & IntraS & InterS \\
\hline \multirow[t]{3}{*}{ Ps } & 15 & $1.3 \pm 0.3$ & - & $a b$ & $1.2 \pm 0.2$ & $a$ & $a$ \\
\hline & 35 & $1.5 \pm 0.3$ & - & $a b$ & $1.4 \pm 0.1$ & $a b$ & a \\
\hline & 100 & $1.6 \pm 0.2$ & - & $a b c$ & $1.5 \pm 0.1$ & b & - \\
\hline \multirow[t]{3}{*}{$Q p$} & 15 & $1.0 \pm 0.0$ & - & a & $1.4 \pm 0.1$ & - & $a b$ \\
\hline & 35 & $1.1 \pm 0.1$ & - & c & $1.4 \pm 0.2$ & - & $a b$ \\
\hline & 100 & $1.1 \pm 0.1$ & - & $a b$ & $1.4 \pm 0.2$ & - & - \\
\hline \multirow[t]{3}{*}{$\mathrm{Pa}$} & 15 & $1.6 \pm 0.2$ & - & $b$ & $1.6 \pm 0.1$ & - & c \\
\hline & 35 & $1.7 \pm 0.2$ & - & a & $1.6 \pm 0.1$ & - & $b c$ \\
\hline & 100 & $1.7 \pm 0.2$ & - & c & $1.6 \pm 0.1$ & - & - \\
\hline \multirow[t]{3}{*}{$C b$} & 15 & $1.1 \pm 0.1$ & - & a & $1.4 \pm 0.1$ & a & $a b$ \\
\hline & 35 & $1.1 \pm 0.1$ & - & c & $1.6 \pm 0.1$ & $b$ & $b c$ \\
\hline & 100 & $1.1 \pm 0.1$ & - & $a$ & $1.6 \pm 0.1$ & $a b$ & - \\
\hline \multirow[t]{3}{*}{$A p$} & 15 & $1.1 \pm 0.1$ & - & $a$ & $1.6 \pm 0.2$ & - & $\mathrm{bc}$ \\
\hline & 35 & $1.1 \pm 0.1$ & - & c & $1.6 \pm 0.1$ & - & $a b c$ \\
\hline & 100 & $1.1 \pm 0.1$ & - & a & $1.7 \pm 0.2$ & - & - \\
\hline \multirow[t]{3}{*}{$A a$} & 15 & $1.6 \pm 0.3$ & - & $b$ & $1.8 \pm 0.2$ & - & c \\
\hline & 35 & $1.6 \pm 0.2$ & - & a & $1.8 \pm 0.1$ & - & c \\
\hline & 100 & $1.6 \pm 0.2$ & - & $b c$ & $1.7 \pm 0.1$ & - & - \\
\hline \multirow[t]{3}{*}{ Fs } & 15 & $1.1 \pm 0.1$ & $\mathrm{a}$ & $\mathrm{a}$ & $1.6 \pm 0.1$ & - & $a b c$ \\
\hline & 35 & $1.2 \pm 0.1$ & $a b$ & $\mathrm{bc}$ & $1.6 \pm 0.2$ & - & $a b c$ \\
\hline & 100 & $1.3 \pm 0.2$ & $\mathrm{~b}$ & $a b c$ & $1.7 \pm 0.2$ & - & - \\
\hline
\end{tabular}

biomass increase with increasing light availability. With the exception that under $15 \%$ and $35 \%$ light availability, the total biomass of $P$. sylvestris was significantly lower than that of P. abies and A. alba $(p<0.05)$.

RMF did not increase with increasing light availability for any of the studied species. Nevertheless, there was a general increase in the RMF of conifers with increasing species' shade tolerance (Tab. 1). However, the RMF of $P$. sylvestris was significantly lower than the RMF of P. abies and A. alba only at $35 \%$ and $100 \%$ light availability $(p<0.05)$. No relationships were observed between the biomass allocation to roots and species' shade tolerance for deciduous species. Only the RMF of A. pseudoplatanus changed significantly with increasing light availability ( $p<0.05$ - Tab. 1). The RMF of $A$. pseudoplatanus was the highest at $100 \%$ light availability, but it was not significantly different from the RMF at $15 \%$ light availability ( $p>0.05)$.

None of the species allocated more biomass towards leaves and needles as a response to decreased light availability (Tab. 1). Light-demanding $P$. sylvestris had the highest LMF along the light gradient. However, it was significantly higher only at $35 \%$ light availability $(p<0.05)$. Q. petrea and $F$. sylvatica, the most light-demanding and the most shade-tolerant of the studied deciduous species, had significantly lower LMF than A. pseudoplatanus and C. betulus. LMF was not related to species shade tolerance and was not different between coniferous and deciduous species.

For most species, biomass allocation to branches remained relatively constant along the light gradient. P. sylvestris and Q. petrea - two of the most light-demanding of the studied species - reacted to increasing light availability by focusing the biomass allocation to branches $(p<0.05-$ Tab. 
1). Even though the BMF of $P$. sylvestris doubled from $15 \%$ to $100 \%$ light availability, it was still the lowest among conifers ( $p<0.05$ under $15 \%$ and 35\% light availability). The changes in BMF of Q. petrea, though statistically significant, were trivial. The stem mass fraction (SMF) of Q. petrea decreased by $35 \%$, on average, with increasing light availability. The SMF of A. pseudoplatanus also decreased with increasing light availability $(p<0.05)$. Other species, except $C$. betulus, showed a similar trend, but the reduction was not significant.

\section{Leaf and plant morphology}

SLA of all studied species decreased with increasing light availability $(p<0.05$ - Fig. 4a, Fig. 4b). However, for P. sylvestris, it was only possible to detect differences from the Kruskal-Wallis test, but not the post-hoc test (for explanation see the Materials and Methods section).

Deciduous trees had significantly higher SLA than coniferous trees ( $p<0.001$ - Fig. 4a, Fig. 4b). The least shade-tolerant conifer species $P$. sylvestris had the lowest SLA along the light gradient (Fig. 4a). SLA of the most shade-tolerant deciduous species F. sylvatica was higher than the SLA of other deciduous species along the light gradient but did not differ significantly from Q. petrea under $15 \%$ light availability and C. betulus under $35 \%$ and $100 \%$ light availability. Hence, the relationship between higher species' shade tolerance and higher SLA for deciduous species was inconclusive.

F. sylvatica was the only species that increased the aboveground box-dimension $(p<0.05)$, i.e., the morphological complexity along the light gradient (Tab. 2). Though a similar trend could be observed for $P$. abies, Q. petrea and P. sylvestris, the increase was not significant for these species.

The belowground box-dimensions of $C$. betulus and $P$. sylvestris seedlings were positively related to increasing light availability $(p<0.05)$. Belowground box-dimensions of $P$. sylvestris increased consistently along the light gradient. Whereas for $C$. betulus, the differences were significant only between $15 \%$ and $35 \%$ light availability $(\mathrm{p}<0.05)$.

Coniferous species had higher aboveground box-dimensions $(1.6 \pm 0.3)$ than the deciduous species $(1.1 \pm 0.1 ; p>0.05-$ Tab. 2). However, there were no significant differences within the coniferous and deciduous species groups ( $p>0.05$ ). Respectively, no relationship between species' shade tolerance and aboveground morphological complexity was found.

The belowground box-dimension of lightdemanding $P$. sylvestris was significantly lower than of the more shade-tolerant conifers $(p<0.001 ; A$. alba $=P$. abies $>P$. sylvestris). A similar relationship was not observed for deciduous species.

\section{Discussion}

\section{Height and diameter growth}

We found differences in relative height and diameter growth between species $(\mathrm{H}$ 1.1), but no pronounced relative height and diameter growth increase with increasing

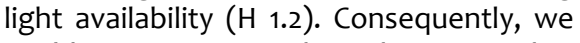
could not support our hypothesis 1.3 - that relative height and diameter growth increase with increasing light availability and that the increase is stronger for the lightdemanding species.

Although shade-tolerant and light-demanding species employ different growth strategies when it comes to limited light conditions, species are known to generally respond to increased light availability by pronounced vertical and lateral growth (Beaudet \& Messier 1998). The lack of a positive effect of light on growth was not anticipated, and is contrary to the vast majority of scientific findings (Claveau et al. 2002, Lilles \& Astrup 2012). This result may be caused by the relatively short time in which the seedlings were exposed to different light conditions. More specifically, we argue that because trees were grown under open field conditions, both in the nursery and for the first year of the experiment, a delayed response to limited light availability is likely (Welander \& Ottosson 1998, Sevillano et al. 2016). The short exposure time might have affected both relative height and diameter growth along the light gradient and the species-specific growth rates. Hence, we expect to see intra- and inter-specific differences that are more pronounced at the later stages of the experiment.

\section{Biomass production and allocation}

Total biomass increased significantly with increasing light availability for $F$. sylvatica, C. betulus, P. abies, and P. sylvestris. However, we did not find that the increase was more pronounced for light-demanding species. Hence, we can only partly confirm hypothesis 2.1 that the total biomass increases with increasing light availability. The positive effect of light availability on total biomass production has been nearly indisputable (Minotta \& Pinzauti 1996, Chen 1997). However, when studying the growth of young seedlings, the initial size of the seedling might have a more pronounced effect on growth than light availability (Van Couwenberghe et al. 2013).

According to the balanced growth hypothesis (Shipley \& Meziane 2002), we hypothesized that RMF increases, and LMF decreases with increasing light availability (H 2.2). However, neither of the species changed the LMF along the light gradient, and only A. pseudoplatanus slightly increased the RMF. Hence, we could not support the hypothesis. P. sylvestris, the least shade-tolerant species, increased the branch mass fraction with increasing light availability. We did not find it to be a general trend amongst less shade-tolerant spe- cies. Consequently, we could confirm that BMF remains constant for shade-tolerant species, but not that it increases with increasing light availability for all light-demanding species ( $\mathrm{H} 2.3$ ).

Similarly, to the relative height and diameter growth, our results here contradict the common expectations. Even though the balanced growth hypothesis has been widely confirmed (Reich et al. 1998, Schall et al. 2012), there have also been some studies that did not detect the expected allocation patterns for young seedlings as a function of light or a distinctly improved species performance with increasing light availability (Delucia et al. 1998). Additionally, it is also known that plasticity negatively correlates with tree size (Messier \& Nikinmaa 2000) and that trees are generally expected to have more pronounced differences in shade-tolerance in the seedling stage (Delagrange et al. 2004). However, some authors have found that young seedlings are well adapted to low light conditions, regardless of the presumed shade tolerance (Pacala et al. 1994, Welander \& Ottosson 1998).

Therefore, we argue that the main reason for this is a high adaptive potential of seedlings to low light conditions and the short time since plants were exposed to limited light. Combined with the high vigor of the seedlings grown in nurseries under favorable conditions and full light, this has most likely facilitated the delayed response.

\section{Leaf and plant morphology}

We found that SLA increased with increasing light availability, which confirms our hypothesis 3.1 and is in line with previous studies (Poorter 1999, Petritan et al. 2009). Leaves are the most plastic plant organ (Poorter et al. 2012) and, thus, the first to show adaptations to the changing light environment. Therefore, when light availability is low, trees increase their photosynthetic surface area by forming lighter or larger leaves, or both, thus increasing the SLA (Gommers et al. 2013, Sevillano et al. 2016).

Shade tolerant species growing in temperate forests tend to have generally higher SLA than less shade-tolerant species (Delucia et al. 1998, Sevillano et al. 2016). Although our findings were inconclusive, we did observe that A. alba and F. sylvatica, the most shade-tolerant species, had the highest SLA, among the coniferous and deciduous species. However, the SLA did not yet continue to gradually decrease with decreasing species' shade tolerance rankings. Therefore, we can only partly confirm our hypothesis that the shade-tolerant species have a higher SLA (H 3.2). Higher SLA of shade-tolerant species contributes to the light interception at a lower cost via the production of leaf area, while less shadetolerant species prioritize investing in more durable leaves (higher leaf life-span) and thus have lower SLA (Janse-Ten Klooster et al. 2007). The differences can be partly ex- 
plained by higher phenotypic plasticity (e.g., leaf size) of shade-tolerant species and higher physiological plasticity (e.g., maximum photosynthetic rate) of light-demanding species (Valladares et al. 2007).

In our study, conifer seedlings had higher aboveground box-dimensions on average $(D b=1.6)$ compared to the seedlings of deciduous tree species $(\mathrm{Db}=1.1-$ Tab. 2$)$. The box-dimension values can theoretically range from one to three, and values close to one indicate that the deciduous trees were nearly branch-less and rather polelike (Seidel et al. 2019b). However, the BMF of $C$. betulus and $F$. sylvatica ranged from $6-10 \%$, on average, but still had box-dimensions of only 1.1. The low box-dimension values are because, overall, there were hardly any branches, and they were small and with very few bifurcations. Higher boxdimensions of the coniferous species are most likely a result of branch whorls, characteristic to all of the studied conifers, and have been reported before (Seidel 2018). Having whorls resulted in more developed crowns with multiple orders of branches, as opposed to all the deciduous species, except $F$. sylvatica. In the upcoming years, we expect that also the deciduous trees will form more complex structures via increased branching.

Only the aboveground structural complexity of $F$. sylvatica increased along the light gradient. This finding is in line with previous studies which found $F$. sylvatica to have higher morphological plasticity than less shade-tolerant species (Valladares et al. 2002, Schall et al. 2012). Surprisingly, no other species reacted to increased light availability yet, and our hypothesis that structural complexity of plant architecture increases with increasing light availability (H 3.3) could only be supported for F. sylvatica, but not for the other species. Trees are expected to promote branch growth in order to optimize light interception (Givnish 1988) and not to lose contact with the light (Annighöfer et al. 2017). However, when the light availability is not limited, trees are to develop closer to their genetically predefined structure (Seidel et al. 2019a). Hence, differences in the structural complexity of plant architecture, mainly in terms of branch formation of plants, are expected along the light gradient.

$P$. sylvestris and $C$. betulus were the only species to show increased belowground structural complexity with increasing light. However, we are aware of several limitations when using box-dimensions (calculated from 3D point clouds) for belowground structural complexity assessment. Firstly, when assessing root structural complexity using a destructive harvest, we are not able to assess the actual root distribution in soil. Secondly, the laser beams $\left(\varnothing_{3}\right.$ $\mathrm{mm}$ ) might not hit the finer roots or refract if the roots are not completely dry, thus leading to possible underestimations. Therefore, we would interpret these findings with caution.
Since there was a limited response in structural complexity of plant architecture along the light gradient after one year of exposure to different light conditions, we also could not confirm that the structural complexity of light-demanding species increases more with increasing light availability (H 3.4). Such an outcome was expected because of the more pronounced effect of light limitation and hence, a stronger response of light-demanding species to reduced light stress.

Similarly, as with growth and biomass allocation patterns, we argue that the short time (one vegetation period) spent under shaded conditions is the main reason for the delayed response in intraspecific differences of structural complexity of plant architecture. Additionally, we expect that trees will develop more complex crowns, and the differences will become more pronounced with ontogeny (Welander \& Ottosson 1998, Hofmann \& Ammer 2008).

\section{Conclusions}

In our study, we could not generally observe the expected effect of light availability on growth rates, biomass allocation patterns, and structural complexity of plant architecture or see pronounced differences between tree species with varying shade tolerance. Nevertheless, we found the initial adaptation all species made by increasing SLA with decreasing light availability. Assuming the potentially delayed reaction of less plastic plant organs, we have a reason to assume that in the following stages of the experiment, we will see increasingly pronounced effects in the morphological adaptations of the tree species. We also expect that the intra- and interspecific differences will become stronger with time.

\section{Acknowledgements}

We thank the technicians of the Department of Silviculture and Forest Ecology of the Temperate Zones, University of Göttingen, Germany for assistance with sampling and data collection and student assistants for scanning the seedlings and processing the point clouds. In addition, we thank the anonymous reviewers of the manuscript for recommendations and constructive comments.

\section{Funding}

This work was supported by The German Research Foundation (DFG) through Grant SE 2383/5-1 provided to Dominik Seidel.

\section{References}

Annighöfer P, Petritan AM, Petritan IC, Ammer C (2017). Disentangling juvenile growth strategies of three shade-tolerant temperate forest tree species responding to a light gradient. Forest Ecology and Management 391: 115-126. - doi: 10.1016/j.foreco.2017.01.010

Archibald S, Bond WJ (2003). Growing tall vs. growing wide: tree architecture and allometry of Acacia karroo in forest, savanna, and arid environments. Oikos 102: 3-14. - doi: 10.1034/j.16
00-0706.2003.12181.X

Beaudet M, Messier C (1998). Growth and morphological responses of yellow birch, sugar maple, and beech seedlings growing under a natural light gradient. Canadian Journal of Forest Research 28: 1007-1015. - doi: 10.1139/x98077

Borges RM (2008). Plasticity comparisons between plants and animals: concepts and mechanisms. Plant Signaling and Behavior 3: 367-375. - doi: 10.4161/psb.3.6.5823

Bradshaw AD (1965). Evolutionary significance of phenotypic plasticity in plants. In: "Advances in Genetics", vol. 13 (Caspari EW, Thoday JM eds). Elsevier, London, UK, pp. 115-155. [online] URL: http://books.google.com/books?id=KEbb Hml一UZUC

Canham CD, Berkowitz AR, Kelly VR, Lovett GM, Ollinger SV, Schnurr J (1996). Biomass allocation and multiple resource limitation in tree seedlings. Canadian Journal of Forest Research 26: 1521-1530. - doi: 10.1139/x26-171

Chen HYH (1997). Interspecific responses of planted seedlings to light availability in interior British Columbia: survival, growth, allometric patterns, and specific leaf area. Canadian Journal of Forest Research 27: 1383-1393. - doi: 10.1139/x97-099

Claveau Y, Messier C, Comeau PG, Coates KD (2002). Growth and crown morphological responses of boreal conifer seedlings and saplings with contrasting shade tolerance to a gradient of light and height. Canadian Journal of Forest Research 32: 458-468. - doi: 10.1139/x01220

Collet C, Chenost C (2006). Using competition and light estimates to predict diameter and height growth of naturally regenerated beech seedlings growing under changing canopy conditions. Forestry 79: 489-502. - doi: 10.1093/forestry/cplo33

Delagrange S, Messier C, Lechowicz MJ, Dizengremel P (2004). Physiological, morphological and allocational plasticity in understory deciduous trees: importance of plant size and light availability. Tree Physiology 24: 775-784. - doi: 10.1093/treephys/24.7.775

Delagrange S, Montpied P, Dreyer E, Messier C, Sinoquet $H$ (2006). Does shade improve light interception efficiency? A comparison among seedlings from shade-tolerant and -intolerant temperate deciduous tree species. The New Phytologist 172: 293-304. - doi: 10.1111/j.14698137.2006.01814.x

Delucia EH, Sipe TW, Herrick J, Maherali H (1998). Sapling biomass allocation and growth in the understory of a deciduous hardwood forest. American Journal of Botany 85: 955-963. doi: $10.2307 / 2446362$

Ellenberg H, Leuschner C (2010). Vegetation Mitteleuropas mit den Alpen in ökologischer, dynamischer und historischer Sicht [The Vegetation of Central Europe Including the Alps from an Ecological, Dynamic, and Historical Perspective]. 6, Auflage, UTB Botanik, Ökologie, Agrarund Forstwissenschaften, Geographie. Verlag Eugen Ulmer, Stuttgart, Germany, pp. 1357. [in German] [online] URL: http://books.google. com/books?id=PrSeDQAAQBAJ

Endara M-J, Coley PD (2011). The resource availability hypothesis revisited: a meta-analysis. 
Functional Ecology 25: 389-398. - doi: 10.1111/j.13 65-2435.2010.01803.x

Givnish TJ (1988). Adaptation to sun and shade: a whole-plant perspective. Functional Plant Biology 15: 63-92. - doi: 10.1071/PP9880063

Gommers CMM, Visser EJW, St Onge KR, Voesenek LACJ, Pierik R (2013). Shade tolerance: when growing tall is not an option. Trends in Plant Science 18: 65-71. - doi: 10.1016/j.tplants.20 12.09.008

Hofmann R, Ammer C (2008). Biomass partitioning of beech seedlings under the canopy of spruce. Austrian Journal of Forest Science 125: 51-66. [online] URL: http://www.researchgate. net/publication/255879940

Janse-Ten Klooster SH, Thomas EJP, Streck FJ (2007). Explaining interspecific differences in sapling growth and shade tolerance in temperate forests. Journal of Ecology 95: 1250-1260. doi: 10.1111/j.1365-2745.2007.01299.x

Kozlowski TT, Pallardy SC (1997). Growth control in woody plants. Academic Press, San Diego, USA, pp. 641. [online] URL: http://books.goo gle.com/books?id=BwP4lAPBykcC

Lambers H, Chapin FS, Pons TL (2008). Plant physiological ecology ( $2^{\text {nd }}$ edn). Springer, New York, New York, USA, pp. 604.

Lilles EB, Astrup R (2012). Multiple resource limitation and ontogeny combined: a growth rate comparison of three co-occurring conifers. Canadian Journal of Forest Research 42: 99-110. doi: 10.1139/x11-163

Mandelbrot BB (1982). The fractal geometry of nature. W. H. Freeman, San Francisco, CA, USA, pp. 460.

Messier C, Nikinmaa E (2000). Effects of light availability and sapling size on the growth, biomass allocation, and crown morphology of understory sugar maple, yellow birch, and beech. Écoscience 7: 345-356. - doi: 10.1080/119 56860.2000 .11682604

Minotta G, Pinzauti S (1996). Effects of light and soil fertility on growth, leaf chlorophyll content and nutrient use efficiency of beech (Fagus sylvatica L.) seedlings. Forest Ecology and Management 86: 61-71. - doi: 10.1016/S0378-1127(96) 03796-6

Pacala SW, Canham CD, Silander Jr JA, Kobe RK (1994). Sapling growth as a function of resources in a north temperate forest. Canadian Journal of Forest Research 24: 2172-2183. - doi: 10.1139/x94-280

Petritan AM, Von Lüpke B, Petritan IC (2009). Influence of light availability on growth, leaf morphology and plant architecture of beech (Fagus sylvatica L.), maple (Acer pseudoplatanus L.) and ash (Fraxinus excelsior L.) saplings. European Journal of Forest Research 128: 61-74. doi: $10.1007 /$ s10342-008-0239-1
Pham B, McConnaughay K (2013). Environmental selection and convergent evolution of plant phenotypes. In: "Ecology and the Environment" (Monson RK ed). Springer, New York, USA, pp. 1-20.

Poorter H, Niklas KJ, Reich PB, Oleksyn J, Poot P, Mommer $L$ (2012). Biomass allocation to leaves, stems and roots: meta-analyses of interspecific variation and environmental control. The New Phytologist 193: 30-50. - doi: 10.1111/j.1469-8137. 2011.03952.x

Poorter L (1999). Growth responses of 15 rainforest tree species to a light gradient: the relative importance of morphological and physiological traits. Functional Ecology 13: 396-410. doi: 10.1046/j.1365-2435.1999.00332.x

Pothier D, Prévost M (2002). Photosynthetic light response and growth analysis of competitive regeneration after partial cutting in a boreal mixed stand. Trees 16: 365-373. - doi: 10.100 7/s00468-001-0158-y

Prasad MNV (1997). Plant ecophysiology. John Wiley and Sons, New York, USA, pp. 542.

Reffye P, Houllier F, Blaise F, Barthelemy D, Dauzat J, Auclair D (1995). A model simulating above- and below-ground tree architecture with agroforestry applications. Agroforestry Systems 30: 175-197. - doi: 10.1007/BF00708920 Reich PB, Tjoelker MG, Walters MB, Vanderklein DW, Buschena C (1998). Close association of RGR, leaf and root morphology, seed mass and shade tolerance in seedlings of nine boreal tree species grown in high and low light. Functional Ecology 12: 327-338. - doi: 10.1046/j.1365-2435.19 98.00208.x

Schall P, Lödige C, Beck M, Ammer C (2012). Biomass allocation to roots and shoots is more sensitive to shade and drought in European beech than in Norway spruce seedlings. Forest Ecology and Management 266: 246-253. - doi: 10.1016/j.foreco.2011.11.017

Seidel D, Beyer F, Hertel D, Fleck S, Leuschner C (2011). 3D-laser scanning: a non-destructive method for studying above- ground biomass and growth of juvenile trees. Agricultural and Forest Meteorology 151: 1305-1311. - doi: 10.1016/ j.agrformet.2011.05.013

Seidel D (2018). A holistic approach to determine tree structural complexity based on laser scanning data and fractal analysis. Ecology and Evolution 8: 128-134. - doi: 10.1002/ece3.3661

Seidel $D$, Annighöfer $P$, Stiers $M$, Zemp CD, Burkardt K, Ehbrecht $M$, Willim K, Kreft H, Hölscher D, Ammer C (2019a). How a measure of tree structural complexity relates to architectural benefit-to-cost ratio, light availability, and growth of trees. Ecology and Evolution 9: 71347142. - doi: $10.1002 /$ ece 3.5281

Seidel D, Ehbrecht M, Dorji Y, Jambay J, Ammer
C, Annighöfer P (2019b). Identifying architectural characteristics that determine tree structural complexity. Trees 33: 911-919. - doi: 10.100 7/s00468-019-01827-4

Sevillano I, Short I, Grant J, O’Reilly C (2016). Effects of light availability on morphology, growth and biomass allocation of Fagus sylvatica and Quercus robur seedlings. Forest Ecology and Management 374: 11-19. - doi: 10.1016/j.for eco.2016.04.048

Shipley B, Meziane D (2002). The balancedgrowth hypothesis and the allometry of leaf and root biomass allocation. Functional Ecology 16: 326-331. - doi: 10.1046/j.1365-2435.2002. 00626.x

Valladares F, Chico J, Aranda I, Balaguer L, Dizengremel P, Manrique E, Dreyer E (2002). The greater seedling high-light tolerance of Quercus robur over Fagus sylvatica is linked to a greater physiological plasticity. Trees 16: 395403. - doi: 10.1007/s00468-002-0184-4

Valladares F, Gianoli E, Gómez JM (2007). Ecological limits to plant phenotypic plasticity. The New Phytologist 176: 749-763. - doi: 10.1111/j.14 69-8137.2007.02275.x

Valladares F, Niinemets U (2008). Shade tolerance, a key plant feature of complex nature and consequences. Annual Review of Ecology, Evolution, and Systematics 39: 237-257. - doi: 10.1146/annurev.ecolsys.39.110707.173506

Van Couwenberghe R, Gégout J-C, Lacombe E, Collet $C$ (2013). Light and competition gradients fail to explain the coexistence of shade-tolerant Fagus sylvatica and shade-intermediate Quercus petraea seedlings. Annals of Botany 112: 1421-1430. - doi: 10.1093/aob/mct200

Van Der Zande D, Jonckheere I, Stuckens J, Verstraeten WW, Coppin P (2008). Sampling design of ground-based lidar measurements of forest canopy structure and its effect on shadowing. Canadian Journal of Remote Sensing 34: 526-538. - doi: 10.5589/mo8-070

Walters MB, Reich PB (1996). Are shade tolerance, survival, and growth linked? Low light and nitrogen effects on hardwood seedlings. Ecology 77: 841-853. - doi: 10.2307/2265505 Welander NT, Ottosson B (1998). The influence of shading on growth and morphology in seedlings of Quercus robur L. and Fagus sylvatica L. Forest Ecology and Management 107: 117-126. doi: 10.1016/S0378-1127(97)00326-5

Zhang L, Copini P, Weemstra M, Sterck F (2016). Functional ratios among leaf, xylem and phloem areas in branches change with shade tolerance, but not with local light conditions, across temperate tree species. The New Phytologist 209: 1566-1575. - doi: 10.1111/nph.13731 